\title{
Comparison of CST with different hours of storage in the Australian National Electricity Market
}

\author{
Yunyang $\mathrm{Wu}{ }^{\mathrm{a}}$, Luke J. Reedman ${ }^{\mathrm{b}}$, Mark A. Barrett ${ }^{\mathrm{a}}$, and Catalina Spataru ${ }^{\mathrm{a}}$ \\ a Energy Institute, University College London, London, UK \\ Central House, 14 Upper Woburn Place, London WC1H ONN \\ Email: yunyang.wu.12@ucl.ac.uk \\ Email: mark.barrett@ucl.ac.uk \\ Email: c.spataru@ucl.ac.uk \\ ${ }^{b}$ CSIRO, Newcastle, Australia \\ CSIRO Energy Centre, 10 Murray Dwyer Circuit, Mayfield West NSW 2304 Australia \\ Email: luke.reedman@csiro.au \\ * Corresponding author
}

\begin{abstract}
The recent ratification of the Paris Climate Change Agreement has significant implications for Australia given its emissions intensive economy. It is likely that the electricity sector will need to decarbonize for Australia to meet medium- and long-term emissions reduction targets. This paper explored the potential role of Concentrating Solar Thermal (CST) in a 100 per cent renewable National Electricity Market (NEM) system under different scenarios of CST configuration and subjected the results to sensitivity analysis.
\end{abstract}

A Genetic algorithm (GA) was chosen as the optimization algorithm to seek the least cost combination of renewable generation technologies, transmission interconnectors and storage capacity in the NEM system at hourly temporal resolution. The main finding is that the scenario where all three CST configurations (six, nine, and twelve hours of thermal storage) can be deployed achieves a lower system cost than scenarios where the size of thermal storage coupled with CST is limited to one option. The results are sensitive to assumptions of the discount rate, renewable resource availability, and the cost of CST technology. This paper found that meeting demand during winter evenings is the most challenging time period for a 100 per cent renewable NEM power system.

Keywords: Energy modelling, optimization, 100 per cent renewables, least cost scenarios

\section{Highlights}

1. Co-optimization renewable system with transmission expansion.

2. Multiple CST configurations considered - six, nine, and twelve hours of thermal storage.

3. At $5 \%$ discount rate, average electricity cost is $\$ 75 / \mathrm{MWh}$ when all CST technologies are available.

4. Results are sensitive to the discount rate, renewable resource availability, and the cost of CST technology. 


\section{Introduction}

In October 2016, the Paris Climate Change Agreement was ratified. The main aim of the "Paris Agreement" is to limit global average temperature rise this century to well below 2 degrees Celsius and to pursue efforts to limit the temperature increase even further to 1.5 degrees Celsius above pre-industrial levels. This has significant implications for Australia given its emissions intensive economy [1].

Australia's high ranking in emissions per capita is mainly due to coal-fired electricity generation which accounts for 72.8 per cent of electricity generation in 2015 [2]. The dominance of coal masks Australia's rich diversity of renewable energy resources (wind, solar, geothermal, hydro, wave, tidal, bioenergy). Except for hydro and wind energy which currently account for most renewable generation connected to the transmission system, these resources are largely undeveloped and could contribute significantly to Australia's future energy supply [3].

While hydro, biomass, wind and solar photovoltaic (PV) are considered mature renewable technologies, other less deployed technologies such as Concentrating Solar Thermal (CST), enhanced geothermal systems, wave and tidal may become more attractive in the future due to less variability and less unpredictability in their output. These characteristics could prove more desirable in a high penetration renewable power system with significant deployment of wind and solar PV.

Studies examining 100 per cent or zero emission renewable electricity systems are a relatively recent development in the literature. In the global context, [4-8], examine the extent of renewable resource availability and find that there is sufficient diversity in resource availability to meet a $100 \%$ renewable system although this requires significant infrastructure investment in certain countries to ensure reliability of supply. Similarly, [8] conducted a statistical analysis and found demand reductions through energy efficiency were crucial in meeting a $100 \%$ renewable system by 2050 . In contrast, [5] posit that the high economic growth and hence demand assumed in their work, prevented a $100 \%$ renewable scenario globally on a pure cost basis. That is, sufficient renewable resources remained, but became prohibitive compared to other near-zero emission generation such as carbon capture and storage (CCS).

There are also a number of country studies in the literature. Two U.S. studies $[9,10]$ use an hourly simulation model for a $100 \%$ renewable energy system finding that significant electrification of space and water heating in buildings, private transport and industrial processes is required to substitute for natural gas use. They also identify a critical role for thermal storage and hydrogen in such a system. [11] examined the U.K. positing that some nuclear generation was preferred rather than a $100 \%$ renewable system. It also suggested possible changes to market or regulatory structures that would likely assist the transition to a high penetration renewable system, but did not explicitly model the impacts of the changes themselves.

European studies [12][13][14] also found sufficient diversity of renewable resources across the interconnected continent (particularly hydro and wind) with future links to North Africa 
adding increased solar resources. They also found a key role for biomass, assuming that biomass residues could be stored or biofuels obtained after conversion can provide longerterm storage, implying year-round availability. Other European country studies for Denmark [16] , Germany [17], Ireland [18] and Portugal [21] that used hourly temporal simulation models at different spatial scales, were more focussed on diversity on the supply side and had limited consideration of possible transmission constraints.

In examining a $100 \%$ renewable energy system in China, [15] highlighted some challenges in accessing sufficient data to evaluate the potential for some renewable resources such as geothermal, wave and tidal energy. Few studies in the literature explicitly consider the impact of demographic change (e.g., ageing of the population) on future electricity demand, although the Japanese study [19] is a notable exception. For New Zealand, [20] model a $100 \%$ renewable electricity system considering wind, biomass, geothermal and hydro resources, and find a crucial role for biogas as a storage medium, for use in gas turbine peaking plant.

Previous studies in the Australian context, the main focus of this paper, have explored different facets of 100 per cent renewable electricity systems. [22] considered such a system by 2020 and focused on whether there is sufficient renewable resources available and if sufficient capacity can be deployed rather than the specific policy or regulatory measures that would drive the transition. In a comprehensive study, [23] found a 100 per cent renewable power system was technically and economically feasible using a potentially wide range of renewable technologies in the National Electricity Market (NEM). [24-26] examined whether it is technically feasible to meet electricity demand with estimated renewable generation output based on historical data of demand and primary renewable resource availability in the NEM. [27] used mesoscale numerical weather models to examine cross-correlations between solar and wind generation with demand for the state of Victoria. [28] find that incremental costs of high renewable electricity systems increase approximately linearly as the share grows from zero to $80 \%$, and then demonstrate a small degree of non-linear escalation, related to the inclusion of more costly renewable technologies such as solar thermal electricity. Analysis by [29] suggests that the market price cap may have to rise to ensure supply adequacy in the energy-only market of the NEM. In contrast, [30] was more focused on employment gains as renewable energy production tends to be more labour intensive than non-renewable energy production.

Many studies examining high renewable penetration systems do not co-optimize the renewable mix and transmission system expansion in hourly temporal resolution modelling. The co-optimization is useful for system expansion planning, such as the tradeoff that exists between transmission investment, the quality of primary renewable resources, and the capacity of the storage devices. This is important given the large transmission investments that are anticipated to promote power exchange and renewable integration. An exception is [26] where an optimized power system is built up by wind farms, PV, CST with 15 hours storage, existing hydro and bio-fueled gas turbines. It used 2010's historical demand data and projected generators' cost data by AETA [32]. The model used a simplified transmission algorithm, without the capacity constraints imposed on the interconnections. Batteries are not considered in that study. 
Despite a burgeoning literature on 100 per cent renewable electricity systems, no previous studies have explored the impact of CST with different sizing of thermal storage. This paper seeks to address this gap. The purpose of the study is to simulate the role of CST (with different hours of storage) in a 100 per cent renewable system in the National Electricity Market (NEM), the main power system in Australia. It explores CST configurations of six, nine and twelve hours of storage versus battery storage and other renewable technologies to meet a given demand at hourly temporal resolution.

In order to answer these research questions, the model framework developed in [26] is amended with an alternative dispatch module and a new transmission module. Projected demand data for 2030 from AMEO [33] is used, which is based on 2010's demand with additional consideration on demand change in the future. The demand series includes projections of rooftop solar PV installed in the NEM and increased demand from new LNG facilities in the future. Updated cost data of renewable technologies are also used.

The paper is structured as follows. The second section of the paper explains the model and key data assumptions. The third section uses an optimized renewable mix in CST all scenario as a base case to discuss the role of CST in the 100 per cent renewable system. Then the scenarios of different CST hour of storage options are compared. Section four discusses the relative deployment of storage devices when CST cost changes and the sensitivity of the results to different renewable resource availability and demand assumptions is also discussed. Section five concludes.

\section{Model and Data}

\subsection{Renewable technology and battery technology}

This study considers numerous renewable electricity generation technologies: utility-scale solar photovoltaic (PV), onshore and offshore wind, run-of-river hydro and pumped storage hydro, CST (with different hours of thermal storage capacity), biomass (wood or bagasse) and biogas using open cycle gas turbine (OCGT). There are other renewable electricity generation technologies identified in previous studies that are not modelled, including enhanced geothermal systems, hot sedimentary aquifer geothermal systems, or ocean renewables (e.g., wave and tidal).

Hydro, on-shore wind turbines and solar PV are currently the most cost competitive and mature of renewable technologies [34]. Both pumped storage and run-of-river hydro can provide synchronous electricity to the system, which is critically important for frequency control of the power system [35]. Tasmania and the Snowy Mountain region in NSW and Victoria have rich hydro resources which are already exploited, while other regions in Australia lack quality sites. For this reason, the research here does not consider the expansion of hydro capacity in the NEM. The run-of-river and pumped storage hydro capacity data are obtained from the Australian Energy Market Operator (AEMO) data published in 2016 [36]. The study applied the monthly water inflow data and initial storage levels at the beginning of 2010 to the run-of-river hydro generators in the model. The total generation from run-of-river hydro generators is limited to $13 \mathrm{TWh}$ per year. 
AEMO also provide hourly generation traces of wind and single-axis tracking solar PV from 2004 to 2010 at sub-region spatial resolution. The 43 locational polygons are sub-regions of the five NEM regions and provide geographical diversity in resource quality and quantity. Since the spatial resolution of the model used here is at state level, we use the average hourly renewable generation across the polygons for each state. The existing wind farm capacity and solar farm capacity in each region is set as the lower bound in the optimization model. A derating of $6.5 \%$ is included for solar PV outage and panel efficiency over its lifetime [23].

There are three types of CST with storage configurations considered in this study: six, nine and twelve hours of storage. For each CST configuration, a constant derating of $3 \%$ (2\%-5\% is the typical range) was assumed due to outages, in addition to a derating due to degradation over time. The latter is lower for CST than for solar PV and $2 \%$ has been assumed across the installed CST capacity. The 'as-generated' output was converted to 'sent-out' by applying a 7\% derating to account for auxiliary load. The total derating of collected energy is $12 \%$ while the derating of available generation capacity is $3 \%$ [23].

In addition to pumped hydro and CST, we also consider battery storage in our study. The cost of alternative types of battery technologies based on different chemistries is shown in Table 1. Based on the cost we choose Li-Ion battery with 0.9 round trip efficiency since it has the cheapest base case cost in 2030.

Table 1:Batteries cost in 2030 value, source: [37]

\begin{tabular}{lrrrr}
\hline Battery type & $\begin{array}{r}\text { Minimum } \\
\text { (\$/MWh) }\end{array}$ & $\begin{array}{r}\text { Base case } \\
\text { (\$/MWh) }\end{array}$ & $\begin{array}{r}\text { Maximum } \\
\text { (\$/MWh) }\end{array}$ & $\begin{array}{r}\text { Round trip } \\
\text { efficiency }\end{array}$ \\
\hline Li-ion & 152.7 & 196.8 & 279.2 & 0.90 \\
Zinc bromide & 113.9 & 209.2 & 353.4 & 0.75 \\
Advanced lead & 258.5 & 317.1 & 496.8 & 0.90 \\
acid & & & & \\
Molten salt & 155.2 & 264.2 & 415.4 & 0.85 \\
\hline
\end{tabular}

Consistent with [23], two biomass electricity generation technologies are considered in the model: biomass from wood waste, and biogas-fired OCGTs. Similar to conventional thermal generators, biomass wood is modelled as a base-load generator (could generate $80 \%$ of its capacity at any hour, and the hourly generation could be up to the installed capacity if needed). Biogas-fired OCGTs is modelled as a peak-load generator that can ramp to full capacity within the time interval; this utilizes the integral storage of biomass for system management. The maximum allowed capacity of biomass for each region and maximum 2 GW capacity of biogas generators in each state [23]. The total generation of biogas generators is limited at below $5 \mathrm{TWh} / \mathrm{yr}$.

\subsection{Demand and technology cost data}

The AEMO releases annual updates on electricity demand projections as part of its National Electricity Forecasting Report (NEFR) [33]. 50 POE medium data / low data are used in this paper. The NEFR provides electricity consumption forecasts for each NEM region over a 20year forecast period (2017 to 2036). 
The demand for the year 2030 used in our model is 210 TWh. In 2030, the maximum hourly demand in the NEM is projected to be $35 \mathrm{GW}$ while the minimum hourly demand in the NEM is around $14 \mathrm{GW}$.

Table 2 lists the cost data used in the model. All costs are in 2015 Australian dollars.

Table 2:Technology costs in 2030

\begin{tabular}{|c|c|c|c|c|c|}
\hline Technology & Capital Cost $(\$ / k W)$ & $\begin{array}{r}\text { Variable Cost } \\
(\$ / \mathrm{MWh})\end{array}$ & $\begin{array}{r}\text { Fixed Cost } \\
(\$ / \mathrm{kW} / \text { year })\end{array}$ & $\begin{array}{r}\text { Lifetime } \\
\text { (year) }\end{array}$ & Source and Notes \\
\hline Large Scale PV & 1108 & 0 & 25 & 30 & {$[34]$} \\
\hline Onshore Wind & 1917 & 0 & 58 & 30 & [34] \\
\hline Offshore Wind & $\begin{array}{r}\text { Capacity: } \$ 5022 \\
\text { Connection: } \$ 618\end{array}$ & 12 & 75 & 30 & [34] \\
\hline Battery Li-Ion & $\begin{array}{l}\text { PCS: } 336 \$ / k W \\
\text { PSS: } 197 \$ / k W h\end{array}$ & 3.1 & 10 & 10 & [37] \\
\hline CST $6 \mathrm{hr}$ & 2328 & 4 & 30 & 30 & [38] \\
\hline CST 9hr & 2844 & 4 & 30 & 30 & [38] \\
\hline CST $12 \mathrm{hr}$ & 3225 & 4 & 30 & 30 & [38] \\
\hline Biomass Wood & 4036 & 9 & 134 & 30 & fuel cost at $111 \$ / \mathrm{MWh}[23]$ \\
\hline Biogas & 800 & 9 & 4 & 30 & fuel cost at $111 \$ / M W h[23]$ \\
\hline
\end{tabular}

\subsection{Model structure}

\subsubsection{Transmission module}

A transmission module is used to represent the interconnectors between the NEM regions is used in this study. Each NEM region is implemented as a node and connected radially by interconnectors, shown in Figure 1. This simplified structure reflects the topology used operationally in the NEM Dispatch Engine (NEMDE) [39]. Similar with most renewable planning studies [40], a transportation approach is used to simulate the electricity transmission between regions. That is, power can be transferred between interconnected regions up to the MW capacity of each interconnector. Following [41], we assume that the energy loss of the transmission line is $1 \%$ of the electricity transmitted per $100 \mathrm{~km}$.

Within the transmission module, the model resolves regional supply and demand imbalances in each time step from a pre-defined merit order based on minimum distance. For example, the list for NSW is [(NSW, VIC), (NSW, QLD), (NSW, VIC, TAS), (NSW, VIC, SA)]. During the dispatch process, if New South Wales needs to import electricity from other regions, the first preference is Victoria provided there is available surplus electricity and spare capacity on the VIC-NSW interconnector. If there is no available energy or transmission capacity, electricity is then sought from Queensland and so on. This simplified strategy allows any surplus electricity to be exported to the nearest deficit region. 


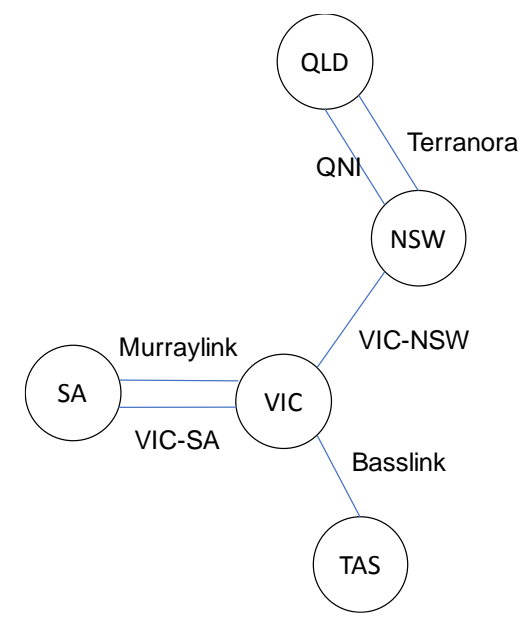

Figure 1: Regional representation of the NEM, source [42]

This module does not model the transmission and distribution network within each region in order to reduce the complexity of the system. It assumes that there are no constraints on the capacity of the transmission and distribution system within each region. The module has the ability to model or optimize new transmission paths (connect two non-adjacent regions) than the current four in NEM regions. However, this will increase the complexity of the model and is beyond the scope of this study.

\subsubsection{Dispatch module}

Similar to [35], the dispatch module considers the non-synchronous generation limit in the system in order to maintain power system stability. Since we assume that future interconnectors between Victoria and Tasmania will remain HVDC, there are two separate synchronous areas in the NEM: The mainland region (Queensland, New South Wales, Victoria, South Australia) and the Tasmania region. The synchronous technologies in this study are biomass, CST, run-of-river hydro, and biogas using OCGT.

The real-time dispatch algorithm used in the NEM is based on the power demand and the bid price stack of all generating units. The model here does not simulate the bid stack for each generator since this is not publicly available data and would increase the computational requirement. We use a simplified dispatch module based on priority dispatch of the nearest available renewable generation. There are three stages in the dispatch module. First is to meet the synchronous demand in the two synchronous areas. The second is meet the remaining demand in the NEM regions. The third is the charging of storage devices if possible.

In the first stage, the process will dispatch the generation from synchronous generators with a priority sequence to meet the mainland and Tasmania synchronous demand. The sequence is biomass base-load component, CST generation, hydro generation and biogas generation. At this stage the electricity can be only exchanged within the mainland area, but not with Tasmania.

In the second stage, five dispatch generation groups are set: 1): baseload biomass, solar PV, on-shore and off-shore wind; 2) CST; 3) pumped hydro and battery devices; 4) run-of-river 
hydro; 5) peak load biogas using OCGT. The remaining demand will be met by its local or regional generation based on the sequence each generation group. That is, local (within region) generation from each generation group is dispatched first to meet demand. If demand cannot be met by local generation, then regional generation from each generation group will be imported subject to interconnector capacity. At the end of each dispatch generation group, the model checks for surplus or deficit. The deficit regions are balanced via power transfer from surplus regions in the following dispatch generation group.

The last stage is that after the demand has been balanced and if there is still any remaining generation from solar PV or wind generators, the module will use the surplus power to charge storage devices subject to constraints on interconnector and storage capacity. After this, any remaining generation from solar PV or wind is spilled. The following shows the overview of the process in the dispatch module:

\section{Frist stage:}

For each area in [Mainland area, Tasmanian area]:

Balance the area's synchronous demand by generation from synchronous generators with the priority sequence

\section{Second stage:}

For each generation group in the sequence of five dispatch generation groups:

For each region in deficit:

balance demand with local generation from the generation group

For each region in deficit:

balance demand with imported regional generation from the generation group subject to interconnector capacity

\section{Third stage:}

For each region with remaining generation from PV or wind: charge local storage devices

For each region with remaining generation from PV or wind: charge regional storage devices subject to interconnector capacity

\subsubsection{Least cost optimization of the system}

The annualized cost of the system is used here as the objective function and is given by:

$$
T C=\sum_{t, r} A C C_{t, r}+\sum_{t, r} F O M_{t, r}+\sum_{t, r} V O M_{t, r} * E_{t, r}+\sum_{i c} A C C_{i c}+\sum \text { Penalty }
$$

where $T C, A C C, F O M$ and $V O M$ represent total cost, annualized capital cost, fixed operating and maintenance (O\&M) cost and variable O\&M cost, respectively. $E$ stands for the electricity output by technology by region. The subscripts $t, r$ stand for technology type (except hydro and pumped hydro as expansion opportunities are limited) and NEM region, respectively. The ic is the index for the four interconnectors. The penalty cost comes from unmet synchronous electricity limit, the unserved demand, excess generation from run-ofriver hydro, biomass and biogas generators. The heavy penalty will guide the optimization to find a generation mix which could follow our assumptions and requirement.

Similar to the approach in [26], a genetic algorithm (GA) is chosen as the optimization 
algorithm to seek the least cost combination of renewable generation, interconnector and storage capacities in the NEM system. The annualized cost of the system is used here as the evaluation function in GA, and GA seeks the lowest value during its evolution.

The GA initializes the capacity mix of the $100 \%$ renewable power system. This mix is then passed to the simulation module. The total annualized cost of generators, batteries and interconnectors is calculated at the end of the dispatch process in the simulation algorithm. Any unserved energy exceeding $0.002 \%$ of the total NEM demand (i.e., the reliability standard in the NEM is that the maximum amount of unserved energy in each region cannot exceed $0.002 \%$ of the energy consumed in each region) is heavily penalized. The GA stores the annualized costs and then 'breeds' a new mix which is simulated and if lower cost this replaces the least cost mix and so the GA iteratively approaches a least cost solution.

No limits are set on the quantum of generation that will evolve in the optimization model. The optimization will stop when the difference in the fitness score between two continuous generations is less than $0.2 \%$.

\section{Result Analysis}

\subsection{Scenario definition}

To find the optimal mix of CST configurations for the NEM, the model deploys the available electricity generation types to minimize total system cost. The paper investigates four scenarios:

- CST all: all renewable electricity generation and storage technologies can be deployed in the optimization. As this paper is primarily interested in the role of potential role of different CST configurations, the scenario is called 'CST all' meaning that the three CST configurations (six, nine, and twelve hours of thermal storage) can be deployed.

- CST6: all non-CST renewable electricity generation and storage technologies can be deployed. The only CST configuration available is CST with six hours of thermal storage.

- CST9: all non-CST renewable electricity generation and storage technologies can be deployed. The only CST configuration available is CST with nine hours of thermal storage.

- CST12: all non-CST renewable electricity generation and storage technologies can be deployed. The only CST configuration available is CST with twelve hours of thermal storage.

\subsection{CST all scenario}

We focus on CST all assuming a 5\% real discount rate to discuss the system behavior of the high penetration renewable system as all generation types in the technology set are available in this scenario. Table 3 lists the estimated capacity of each technology in each NEM region, while 
Table 4 lists the cost performance matrix by each technology in the whole NEM regions.

The total installed capacity in this scenario is $91 \mathrm{GW}$ and the thermal storage in the system is around $166 \mathrm{GWh}$. Onshore wind has the largest capacity (28\%) and generation (34\%) share among all the technologies. This is consistent with other studies in the Australian context that find due to its cost and wind resource geographical diversity, onshore wind has a key role in a $100 \%$ renewable electricity system. There is also $5 \%$ capacity from offshore wind, which contributes around $8 \%$ of the annual consumption. Solar PV has the second largest capacity installed at around 26\%. The generation from solar PV and CST supplies around $43 \%$ of the total demand of the year. There is more capacity installed in CST with 9 or 12 hours of storage then CST with 6 hours of storage. The capacity of the biogas-fired OCGT units reached the maximum allowed limit in all regions. Serving as peak load generators, the biogas generators have the highest levelised cost among all electricity generation technologies because of their low capacity factors.

Table 3: Regional generator capacity in GW, CST all with $5 \%$ discount rate

\begin{tabular}{|c|c|c|c|c|c|c|c|c|c|c|c|}
\hline Region & PV & Wind & $\begin{array}{l}\text { Offshore } \\
\text { Wind }\end{array}$ & CST6 & CST9 & CST12 & Hydro & $\begin{array}{l}\text { Pumped } \\
\text { Hydro }\end{array}$ & Battery & $\begin{array}{l}\text { Biomass } \\
\text { Wood }\end{array}$ & $\begin{array}{l}\text { Biomass } \\
\text { Gas }\end{array}$ \\
\hline New South & 6.8 & 9.5 & 0.0 & 0.8 & 0.0 & 0.8 & 2.3 & 0.8 & 0.0 & 0.1 & 2.0 \\
\hline \multicolumn{12}{|l|}{ Wales } \\
\hline Queensland & 7.3 & 12.9 & 2.9 & 0.1 & 7.3 & 2.6 & 0.2 & 0.5 & 0.0 & 1.0 & 2.0 \\
\hline South & 2.6 & 1.6 & 0.0 & 0.0 & 0.2 & 0.7 & - & - & 0.0 & 0.0 & 2.0 \\
\hline \multicolumn{12}{|l|}{ Australia } \\
\hline Tasmania & 5.9 & 0.3 & 0.0 & 0.0 & 0.0 & 0.0 & 2.2 & - & 0.0 & 0.0 & 2.0 \\
\hline Victoria & 1.0 & 1.5 & 2.1 & 0.7 & 0.0 & 3.2 & 2.2 & - & 0.0 & 1.1 & 2.0 \\
\hline
\end{tabular}

Table 4: Cost and performance matrix by technology in the whole NEM regions, CST all with 5\% discount rate

\begin{tabular}{|c|c|c|c|c|c|c|c|c|c|c|c|}
\hline & PV & Wind & $\begin{array}{l}\text { Offshore } \\
\text { Wind }\end{array}$ & CST6 & CST9 & CST12 & Hydro & $\begin{array}{l}\text { Pumped } \\
\text { Hydro }\end{array}$ & Battery & $\begin{array}{l}\text { Biomass } \\
\text { Wood }\end{array}$ & $\begin{array}{l}\text { Biomass } \\
\text { Gas }\end{array}$ \\
\hline $\begin{array}{l}\text { Capacity } \\
\text { Share }\end{array}$ & $25.9 \%$ & $28.3 \%$ & $5.4 \%$ & $1.8 \%$ & $8.2 \%$ & $8.1 \%$ & $7.5 \%$ & $1.5 \%$ & $0.0 \%$ & $2.3 \%$ & $11.0 \%$ \\
\hline $\begin{array}{l}\text { Generation } \\
\text { Share }\end{array}$ & $24.0 \%$ & $33.7 \%$ & $8.2 \%$ & $2.4 \%$ & $7.9 \%$ & $9.0 \%$ & $6.0 \%$ & $0.5 \%$ & $0.0 \%$ & $7.1 \%$ & $1.3 \%$ \\
\hline $\begin{array}{l}\text { Average } \\
\text { Capacity } \\
\text { Factors }\end{array}$ & $24.9 \%$ & $32.1 \%$ & $40.9 \%$ & $34.7 \%$ & $26.0 \%$ & $29.8 \%$ & $21.6 \%$ & $8.5 \%$ & - & $81.3 \%$ & $3.2 \%$ \\
\hline $\begin{array}{l}\text { Energy Spilled } \\
\text { (GWh) }\end{array}$ & 8207.7 & 11738.6 & 4112.1 & 1160.5 & 13266.5 & 14828.9 & 3833.2 & 0.0 & 0.0 & 0.0 & 0.0 \\
\hline $\begin{array}{l}\text { Total Cost } \\
\text { (Million \$) }\end{array}$ & 2293.3 & 4713.5 & 2386.2 & 323.2 & 1681.0 & 1850.5 & 0.0 & 0.0 & 0.0 & 1106.6 & 892.4 \\
\hline $\begin{array}{l}\text { Levelized Cost } \\
\text { (\$/MWh) }\end{array}$ & 44.5 & 65.0 & 135.4 & 63.8 & 98.4 & 96.0 & - & - & - & 72.7 & 320.6 \\
\hline
\end{tabular}

\subsubsection{Typical summer and winter week dispatch}

Figure 2 and Figure 3 show the dispatch of generation in the CST all scenario for a summer and winter week, respectively. The demand for each region and generation from each technology is accumulated across the NEM, while energy exchange between regions is not shown in these figures. The storage level shows the total amount of energy stored in pumped-hydro, CST and battery devices. The dispatched energy above the demand curve is the energy loss in the transmission. 
The selected summer week has the largest weekly demand during the year. Solar PV and wind generators provided most of the electricity during daytime hours. Wind and CST contribute most of the generation during night time periods. In this week, hydro and biogas generators were running on Monday and Tuesday nights when there is not enough energy stored in CST.

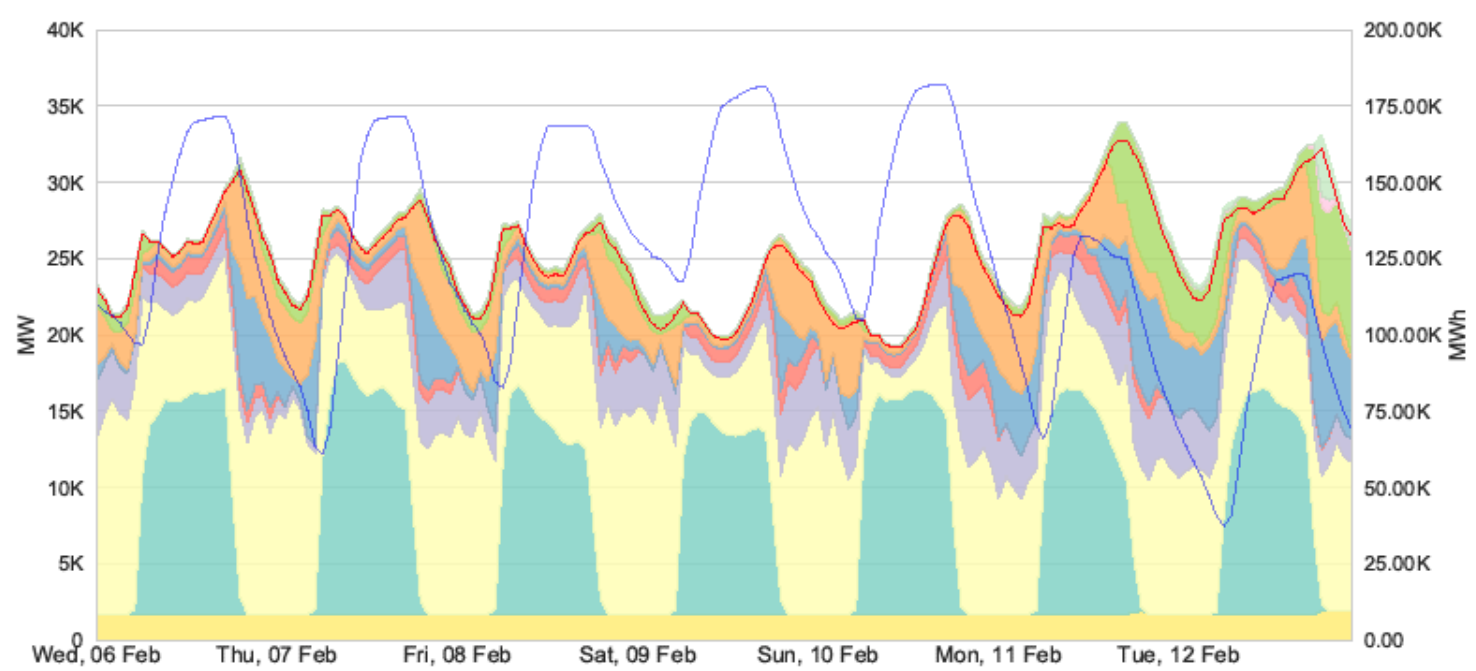

NEM Dispatch

- NEM Demand

- NEM Storage Level

BiomassGas $10 \mathrm{GW}$

Battery $0 \mathrm{GW}$

PumpedHydro $1 \mathrm{GW}$

Hydro $6 \mathrm{GW}$

CST12 $7 \mathrm{GW}$

CST9 $7 \mathrm{GW}$

CST6 $1 \mathrm{GW}$

OffWind $4 \mathrm{GW}$

Wind $25 \mathrm{GW}$

PV $23 \mathrm{GW}$

BiomassWood $2 \mathrm{GW}$

Figure 2: Summer week dispatch in NEM, CST all scenario

For a $100 \%$ renewable electricity system, meeting demand in winter is more challenging than in summer for the NEM. The NEM-wide storage was empty for several nights during the selected challenging winter week. Output from CST is limited by the limited energy collected during daytime hours. Run-of-river hydro and biogas almost ran on most days during this week.

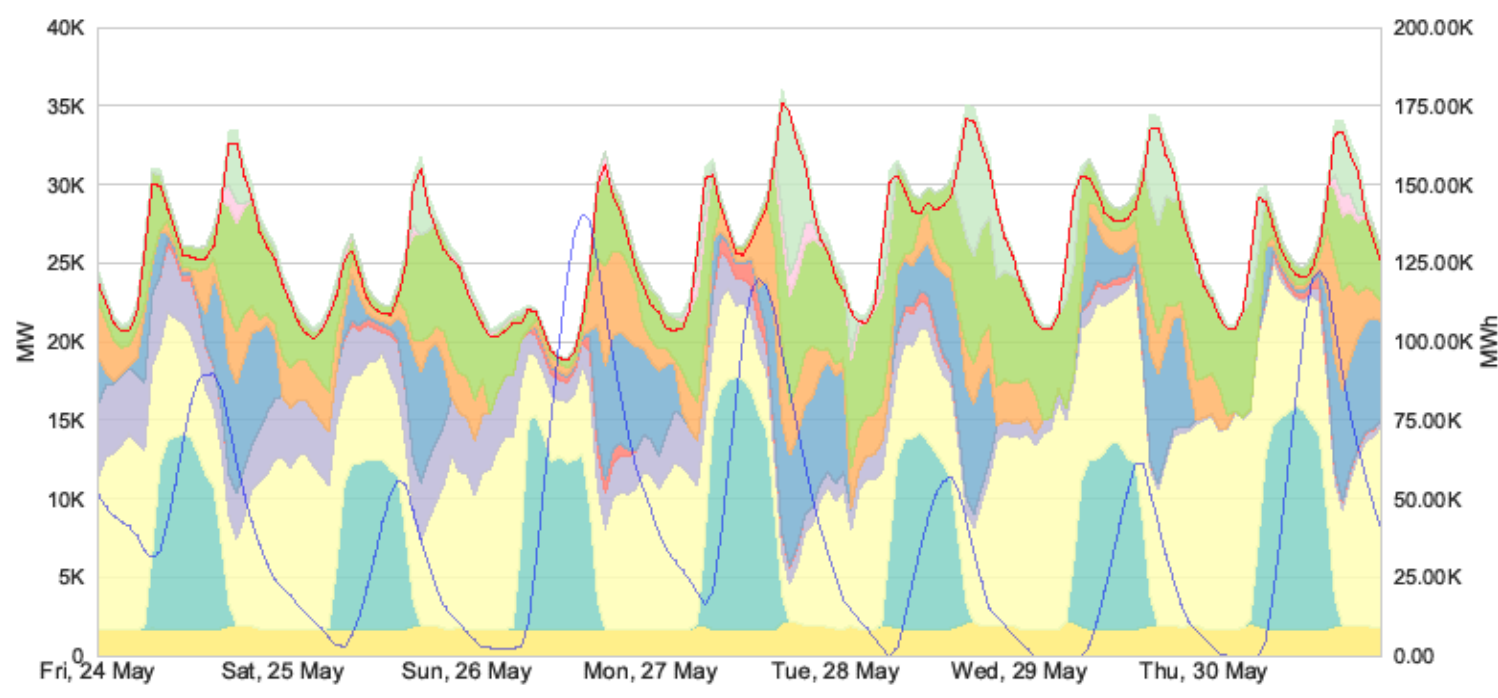

Hydro 6 GW

CST12 7 GW

CST9 $7 \mathrm{GW}$

CST6 $1 \mathrm{GW}$

OffWind $4 \mathrm{GW}$

Wind $25 \mathrm{GW}$

PV 23 GW

BiomassWood $2 \mathrm{GW}$

Figure 3: Winter week dispatch in NEM, CST all scenario

\subsubsection{Interconnectors capacities and energy exchange}


With the majority of the electricity generated from intermittent renewable resources, the transmission system is critically important to balance regional supply and demand. Figure 4 shows the capacities and activities of the interconnectors during the year. The capacities of the interconnectors in NEM regions increase dramatically to support the high renewable energy system. The capacity of the NSW-QLD and VIC-NSW interconnectors increase to around $6000 \mathrm{MW}$ as New South Wales and Victoria are positioned in the 'middle' of the NEM and act as transit states. The capacity of the VIC-TAS interconnector increases from $600 \mathrm{MW}$ to $3388 \mathrm{MW}$, indicating a key role for hydro generation exports from Tasmania to the mainland.

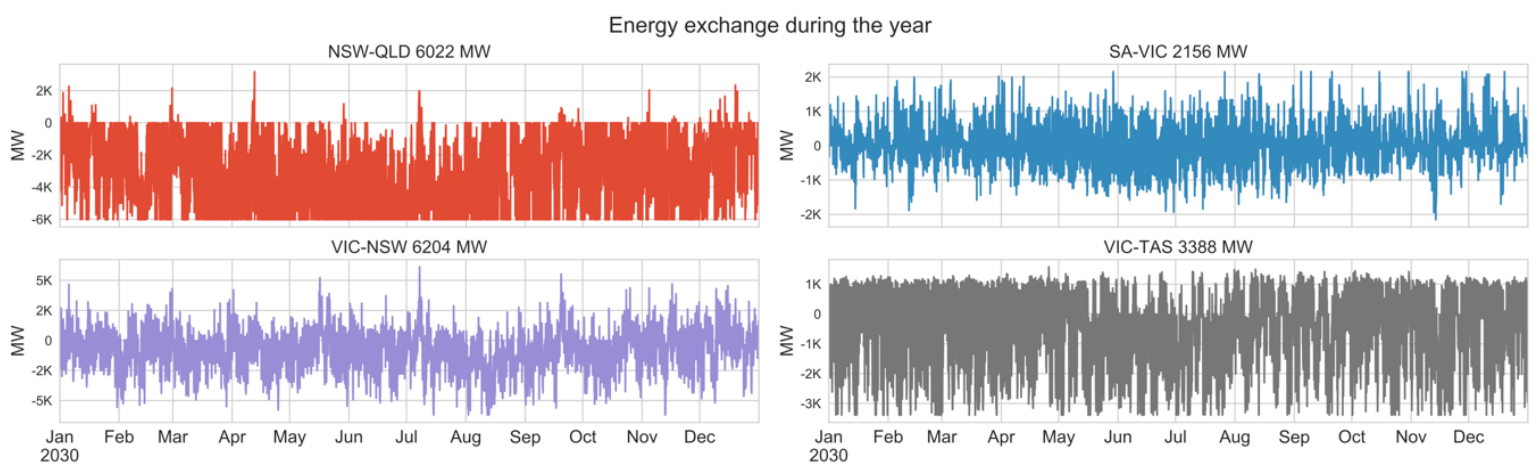

Figure 4: Interconnector flows

Table 5 shows the amount of electricity imported and exported from each region (the electricity transferred via the region is not included to avoid double counting). Queensland and Tasmania are major energy export regions reflecting significant renewable capacity in excess of demand, whereas Victoria and New South Wales are major energy import regions reflecting relatively low levels of capacity relative to demand. These outcomes mainly reflect capacity being installed at prime locations (in terms of renewable resource quality) as regional interconnector capacity is unconstrained.

Table 5: Energy export and import from/to each region

\begin{tabular}{llllll}
\hline Region & New South Wales & Queensland & South Australia & Tasmania & Victoria \\
\hline Import (GWh) & 20172 & 67 & 1453 & 2319 & 11426 \\
Export (GWh) & 3118 & 26533 & 1661 & 7010 & 1794 \\
\hline
\end{tabular}

The cost of transmission expansion increases the system cost by around $\$ 2$ per MWh. This cost is lower than other studies [26,43], as we calculated the cost based on the optimized capacity. This would likely underestimate the real system cost as additional transmission capacity within each region would be required to deliver power to load centres.

\subsubsection{Spilled energy / Biomass gas usage / Challenge week}

The biogas-fired OCGTs that serve as peaking plants are used when there is not enough available electricity generation from other technologies. Accordingly, time periods where biogas OCGTs are dispatched may indicate periods of system stress. Figure 5 shows the daily biogas generation for each region. Biogas is more frequently used during the cooler months, 
especially between May and August. Since solar PV and CST account for around $40 \%$ of system capacity, it is more difficult to meet the system demand with wind farms and hydro facilities after sunset in winter if the storage in CST is low.

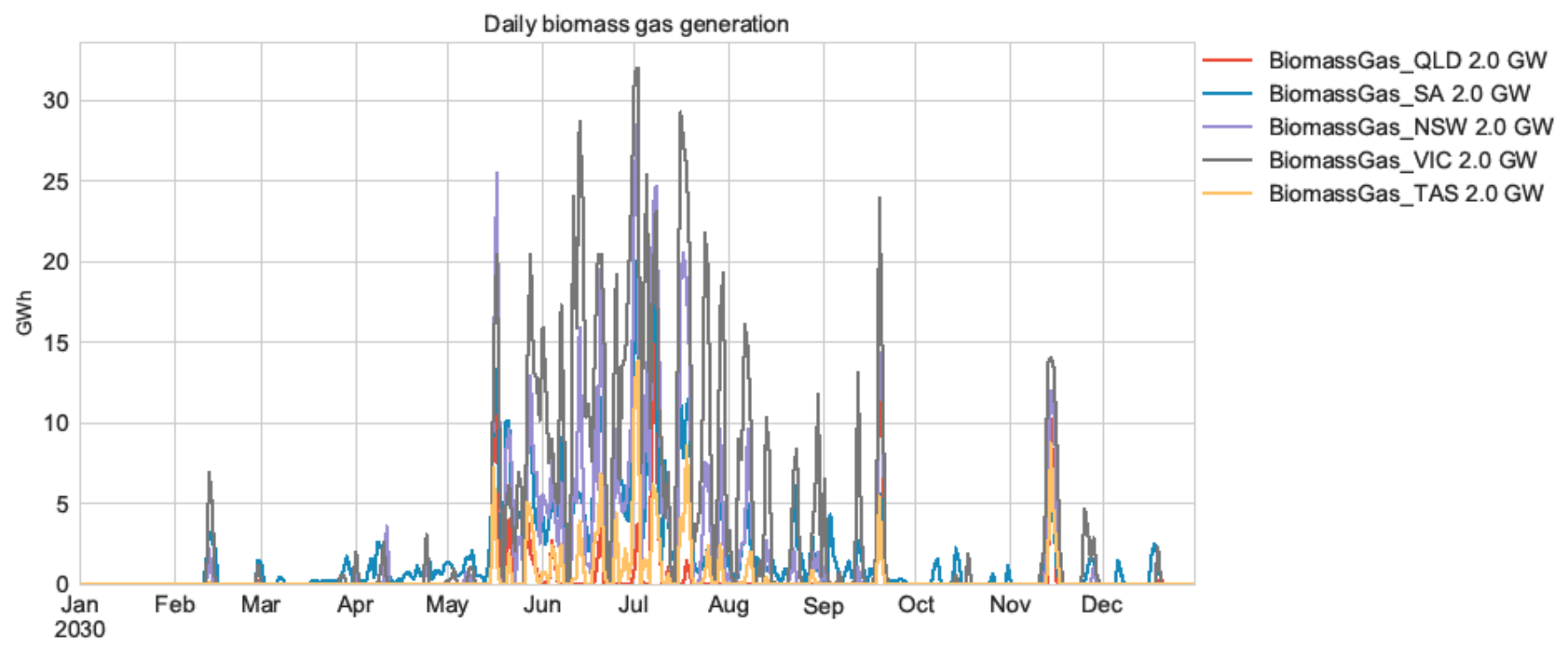

Figure 5: Daily biogas generation

The total spilled energy in the CST all scenario is 53 TWh, around $26 \%$ of the annual demand. More than half of the spilled energy is from CST generators, while wind also contributes more than $22 \%$ of total spilled energy. Due to our dispatch priority, less spilled energy comes from solar PV. Figure 6 shows the spilled energy by technology in each month. It shows that spilled energy from CST exhibits seasonal variation with significant spilled energy in the summer months (when solar irradiance is high) compared to winter months. This suggests that the model is deploying CST capacity mainly as a means to meet winter demand. This aligns with the observation that larger amounts of storage are preferred (nine and twelve hours compared to six). In contrast, the seasonal variation in spilled energy for solar PV and wind is more muted.

Large amounts of spilled energy are common in previous studies of high penetration renewable systems. In [31], the average annual excess power is around double the demand for a 99.9\% renewable system for the PJM system in the eastern United States. It is important to note, consistent with previous studies, no penalty is placed on spilled energy is this study. However, more responsive 'flexible' demand has potential to reduce the amount of spilled energy in a high penetration renewable system. In addition to conventional demand side management, this could include pre-cooling of buildings in summer months, charging of other storage mediums (e.g., hot water systems, ice storage for heating and cooling applications, production of hydrogen for transportation fuels or industrial processes), and the charging of electric vehicles. Another option to reduce spilled generation especially from CST, is to have maintenance outages or reduce output during the summer months. This is the reverse of the current situation in the NEM where thermal power stations (mainly coal-fired) are taken offline during low demand winter months. 


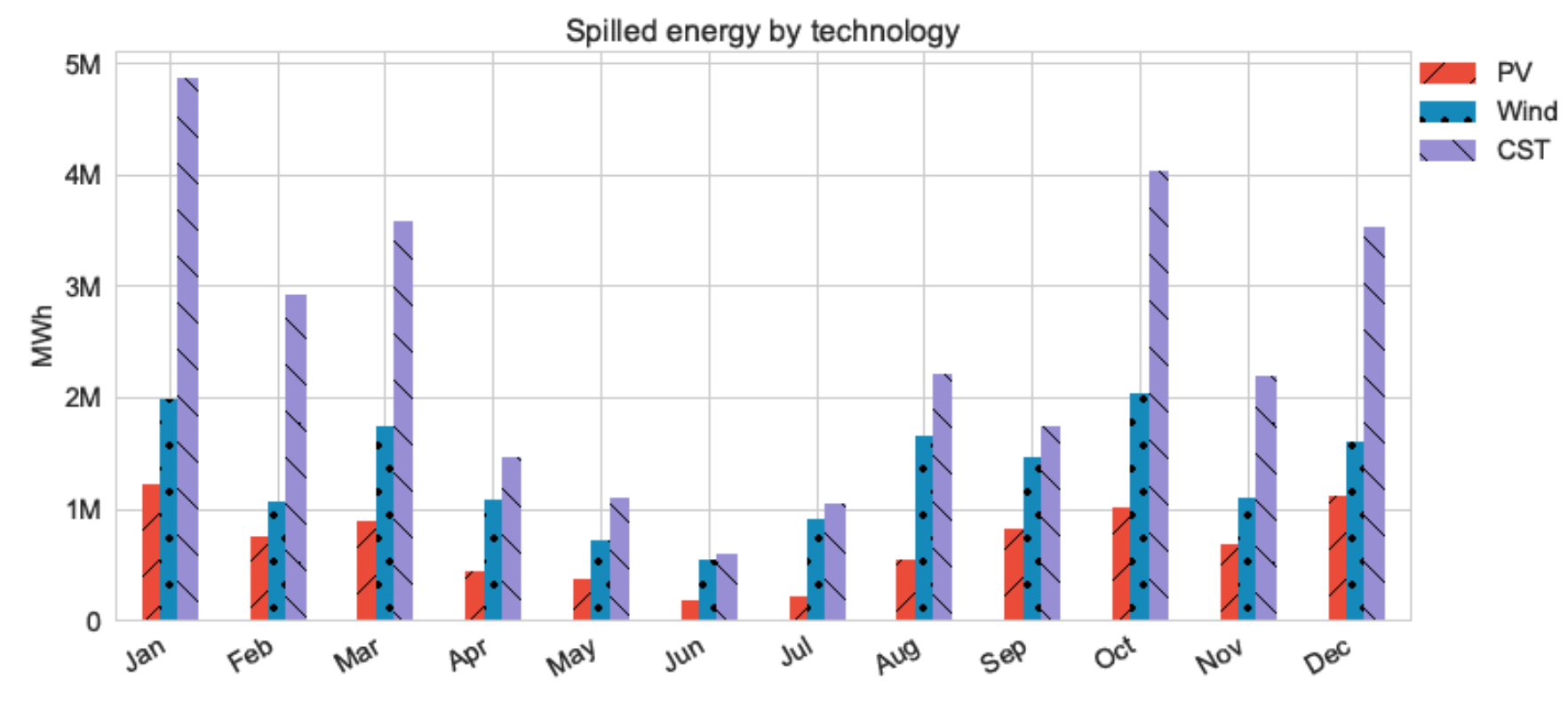

Figure 6: Spilled Energy, each month

\subsection{Comparison of CST with different hours of storage}

We then run the other three scenarios to observe the impacts of reducing the CST options on the technology mix and system cost with $5 \%$ and $10 \%$ real discount rates. Table 6 lists the least cost optimization results of the four scenarios. In general, the scenario with all three types of CST configuration has the least cost of all scenarios. This reflects three factors. First, the levelised cost of CST declines (but not indefinitely) as the number of storage hours increases (increased upfront capital cost is more than offset by improved capacity factor). Second, an increased number of CST configuration options increase the utilisation of each CST plant type. Third, the CST all scenario results in less deployment of solar PV and onshore wind in poorer quality resource regions. This increases the average capacity factor and marginally reduces the levelised cost of electricity generation. It also shows that in the scenarios when only one CST configuration is available, CST12 is the next lowest overall cost.

For both discount rate cases, the capacity of individual technology varies in different scenarios except biomass and biogas. The total capacity of biogas in all four scenarios are all $10 \mathrm{GW}$, which is the maximum allowed capacity in the model used in [23]. The biogas peaking plants are critically important to the system with large share of intermittent renewable generators. Similarly, the capacity of biomass generation has minor variations around the $2.2 \mathrm{GW}$ upper bound in all scenarios. The reason for this is that they could provide least $80 \%$ continuous synchronous generation throughout the year, which is important to meet the synchronous demand together with generation from CST and run-ofriver hydro. There is no deployment of battery storage in the CST all scenario in both discount rate cases. This reflects the multiple CST storage configurations meaning that largescale batteries are not economic given the cost and scenarios assumptions. Another factor is the temporal resolution in this study (i.e., hourly). This likely means that battery storage is undervalued in the modelling compared to a finer temporal resolution model, since 
batteries could provide frequency control ancillary services and faster ramping in shorter time scales.

In the $5 \%$ discount rate case, the capacity share of wind decreases while the share of solar PV increases if CST with longer hours of storage is available. This is because by the year 2030 , the capital cost of large scale solar PV is projected to be lower than wind farms in Table 2, and the system could overcome the night period utilizing CST storage (i.e. the CST plant charges its thermal storage during the day and generates during the night) which reduces the need of generation from wind farms. The total capacity of CST in the CST all scenario is $16.6 \mathrm{GW}$ and its average storage capacity is 10 hours. The total capacity of all CST in CST all scenario is similar to that in the CST9 scenario.

Table 6: Least cost combination for all scenarios, 5\% and 10\% discount rate

\begin{tabular}{lrrrrrrrr}
\hline & \multicolumn{3}{l}{ 5\% Discount Rate } & \multicolumn{7}{c}{ 10\% Discount Rate } \\
\hline & \multicolumn{1}{c}{ CST6 } & CST9 & CST12 & CST all & CST6 & CST9 & CST12 & CST all \\
\cline { 2 - 9 } PV (GW) & 18.8 & 22.9 & 23.4 & 23.6 & 25.8 & 20.8 & 21.5 & 20.8 \\
Onshore Wind (GW) & 36.3 & 28.0 & 22.3 & 25.8 & 30.4 & 33.9 & 33.1 & 31.6 \\
Offshore Wind (GW) & 2.8 & 4.5 & 1.7 & 4.9 & 4.4 & 4.4 & 3.8 & 3.1 \\
Hydro (GW) & 6.9 & 6.9 & 6.9 & 6.9 & 6.9 & 6.9 & 6.9 & 6.9 \\
Pumped Hydro (GW) & 1.3 & 1.3 & 1.3 & 1.3 & 1.3 & 1.3 & 1.3 & 1.3 \\
CST6 (GW) & 21.7 & - & - & 1.7 & 17.2 & - & - & 7.6 \\
CST9 (GW) & - & 18.8 & - & 7.5 & - & 16.5 & - & 4.5 \\
CST12 (GW) & - & - & 26.1 & 7.4 & - & - & 14.9 & 7.8 \\
Biomass (GW) & 2.1 & 2.1 & 1.8 & 2.1 & 2.2 & 2.0 & 2.2 & 2.0 \\
Biogas (GW) & 10.0 & 10.0 & 10.0 & 10.0 & 10.0 & 10.0 & 10.0 & 10.0 \\
Battery Capacity (GW) & 0.1 & 0.3 & 0.0 & 0.0 & 0.6 & 0.0 & 0.0 & 0.0 \\
Battery Storage (GWh) & 0.3 & 1.5 & 0.0 & 0.0 & 3.5 & 0.0 & 0.0 & 0.0 \\
Cost (\$/MWh) & 77.1 & 76.8 & 75.6 & 74.6 & 112.5 & 113.1 & 110 & 109.7 \\
Total Capacity (GW) & 100.0 & 94.7 & 93.5 & 91.2 & 98.8 & 95.8 & 93.7 & 95.6 \\
Spilled (TWh) & 73.8 & 60.1 & 76.2 & 53.3 & 64.1 & 60.7 & 62.4 & 67.1 \\
\hline
\end{tabular}

With the $10 \%$ discount rate, the total capacity of CST in the CST all scenario is $19.9 \mathrm{GW}$ and its average storage is 9 hours. The discount rate is only used to calculate the annualized capital cost for each technology and it does not change the technology's O\&M cost. The main effect of a different discount rate is to change the relationship between the annualized capacity cost and the O\&M cost for the technology [26]. Interestingly we found that the capacity share of wind will be larger while share of PV be smaller if CST with longer hours of storage is used, which is opposite to the result in the $5 \%$ discount rate. The storage size of CST is not the only variable determined, but also its generating capacity.

When comparing the results on a subset of the scenarios (CST9, CST12 and CST all) for the two discount rate cases, the capacity share of solar PV and CST decreases while the share of wind increases when discount rates are higher. The increased wind capacity could offset the inadequate generation caused by decreasing CST storage size during night. However, in the CST6 scenarios, the wind capacity slightly decreased while the share of solar PV largely increased when higher discount rate is used. This is caused by the increased battery storage which could provide sufficient electricity during night. 


\section{Additional sensitivity cases}

\subsection{Impact of CST cost}

The previous results show that CST has a role to play in a 100 per cent renewable NEM system. In the following sensitivity analysis, we scale the cost of CST by $150 \%$ and $200 \%$, while keeping other cost of other technologies unchanged, to test the robustness of these results.

Table 7 summarizes the results for the four CST scenarios with three cost sets. The battery storage size increases and the CST capacity decreases when higher CST costs prevail. The system cost difference between ScaleCST150 and BaseCost is much larger than the difference between ScaleCST200 and ScaleCST150.

It is also observed that in ScaleCST150 and ScaleCST200 the battery storage size increases and CST capacity decreases if the CST with longer hours of storage is used. CST6 scenario has the smallest cost except CST all in the ScaleCST150 and ScaleCST200 cost cases. While in the ScaleCST200 cost case, the CST12 scenario has the highest system cost compared with others. The system cost difference between ScaleCST150 and BaseCost of the four scenario ranges from $6.5 \%$ to $9.5 \%$, while the cost difference between Scale200 and Scale150 only ranges from $2.1 \%$ to $4.1 \%$. The assumed cost of CST has less impact on the system cost when it increases further. This can be explained as the price of CST increases, CST with more storage is less cost competitive compared to a system with some battery storage.

Table 7: CST cost analysis

\begin{tabular}{|c|c|c|c|c|c|c|c|c|c|c|c|c|}
\hline CST Cost & CST6 & & & CST9 & & & CST12 & & & CST all & & \\
\hline & $\begin{array}{l}\text { System } \\
\text { Cost } \\
\$ / \mathrm{MWh}\end{array}$ & $\begin{array}{l}\text { Battery } \\
\text { Storage } \\
\text { GWh }\end{array}$ & $\begin{array}{l}\text { CST } \\
\text { Capacity } \\
\text { GW }\end{array}$ & $\begin{array}{l}\text { System } \\
\text { Cost } \\
\$ / \mathrm{MWh}\end{array}$ & $\begin{array}{l}\text { Battery } \\
\text { Storage } \\
\text { GWh }\end{array}$ & $\begin{array}{l}\text { CST } \\
\text { Capacity } \\
\text { MW }\end{array}$ & $\begin{array}{l}\text { System } \\
\text { Cost } \\
\$ / \mathrm{MWh}\end{array}$ & $\begin{array}{l}\text { Battery } \\
\text { Storage } \\
\text { GWh }\end{array}$ & $\begin{array}{l}\text { CST } \\
\text { Capacity } \\
\text { GW }\end{array}$ & $\begin{array}{l}\text { System } \\
\text { Cost } \\
\$ / \mathrm{MWh}\end{array}$ & $\begin{array}{l}\text { Battery } \\
\text { Storage } \\
\text { GWh }\end{array}$ & $\begin{array}{l}\text { CST } \\
\text { Capacity } \\
\text { GW }\end{array}$ \\
\hline BaseCost & 77.1 & 0.3 & 21.7 & 76.8 & 1.5 & 18.8 & 75.6 & 0 & 26.0 & 74.6 & 0 & 16.5 \\
\hline ScaleCST150 & 82.1 & 7.0 & 11.5 & 83.5 & 17.2 & 9.0 & 82.8 & 24.2 & 7.0 & 81.7 & 15.5 & 8.8 \\
\hline ScaleCST200 & 84.6 & 24.0 & 5.6 & 85.1 & 30.2 & 4.5 & 85.9 & 34.9 & 3.6 & 83.6 & 44.3 & 2.9 \\
\hline
\end{tabular}




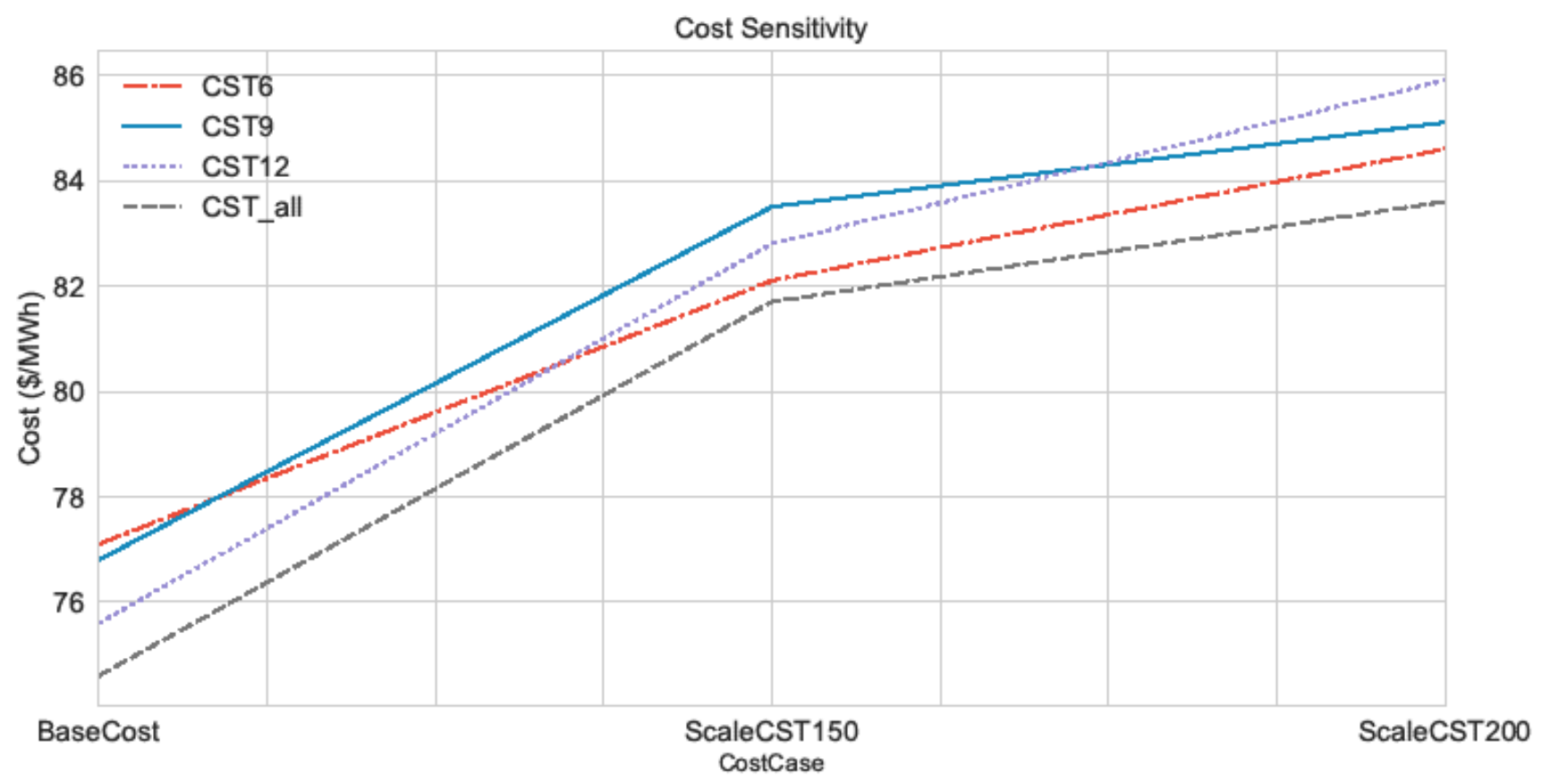

Figure 7: Cost Sensitivity

4.2 Impact of the renewable resources quality for different years

Results that were discussed in previous sections assumed renewable output over the simulated year using historical data for the year 2010. In order to test whether the optimized renewable mix could meet the minimum system reliability requirement (i.e., unserved energy less than $0.002 \%$ of energy consumed per year) in the NEM, the renewable mix from CST all was tested with 2004-2009 renewable profile data (solar PV, onshore and offshore wind, CST).

Two years passed the test without any penalty on excess unserved energy. The maximum unserved energy occurred when the 2007 renewable trace data was assumed, at $0.01 \%$ of the annual demand. The maximum unserved demand in an hour was around $6 \mathrm{GW}$ across 6 years' simulation and this occurred at $6 \mathrm{pm}$ on a Tuesday night in June (Tuesday is typically the highest demand day of the week in the NEM). The biogas-fired OCGTs were operating at full output in that hour. The wind generation or solar PV generation drops sharply while the CST generation is limited by its available storage at the time (typically low during winter). The unserved demand could be met if there is sufficient energy stored in CST at that hour.

This sensitivity result reiterates the finding that meeting demand during winter evenings is the most challenging time period for a 100 per cent renewable NEM power system. It underscores the importance of sufficient capacity of dispatchable renewable generation to be available during winter evenings. It also suggests that more flexible demand may have a critical role to limit the amount of additional capacity required. This in an important avenue for future research. 


\subsection{Impact of rooftop solar PV uptake}

The hourly demand trace used in the analysis thus far has assumed a certain uptake of rooftop solar PV which reduces the demand to be served by renewable generators connected at high voltage, the main focus of this paper. It is possible that the uptake of rooftop solar PV will be greater, and therefore less demand is presented to the wholesale market. Using an alternative scenario of rooftop solar PV uptake given by [33], the future annual demand in the NEM may sharply reduce to $156 \mathrm{TWh}$ (compared to $210 \mathrm{TWh}$ ) due to increasing installation of residential and commercial rooftop solar PV. We test the renewable mix from the CST all scenario with the low demand data. The mix could meet the NEM's demand while the biogas-fired OCGTs in NSW and TAS are not used during the year. The annual cost of the NEM system is lower than the medium demand case as the operation cost is lower. However, the cost per MWh in the NEM is higher as the annual demand is smaller.

In addition, the CST all scenario was re-run with the low demand data, and the estimated system cost is around $\$ 70 / \mathrm{MWh}$. Figure 8 shows the generation dispatch of the optimized renewable mix in the same winter week.

The total capacity of the optimized renewable mix is $66.7 \mathrm{GW}$. The capacity size of biogas peaking plant and biomass does not change significantly. All the biogas-fired power stations reach the allowed maximum capacity limit and the total biomass wood capacity is around $2.1 \mathrm{GW}$.

In the medium demand case, the solar PV and CST share are $26 \%$ and $18 \%$, respectively. The capacity share of PV and CST drops to $23 \%$ and $13 \%$ in the low demand scenario. The share of onshore and offshore wind farms' capacity and generation remains unchanged. The generation share of pumped-hydro and biogas increases due to less CST with storage.

The transmission capacity requirement on the VIC-NSW and VIC-TAS interconnectors are similar to the CST all scenario. There is no expansion requirement on the SA-VIC interconnector, as South Australia has less demand due to the increased deployment of rooftop solar PV. Expansion of the NSW-QLD interconnector is substantially less at 3500 MW. In this case, NSW is still an energy import region and QLD is joined by VIC as an energy export region. TAS and SA remain energy export regions. 


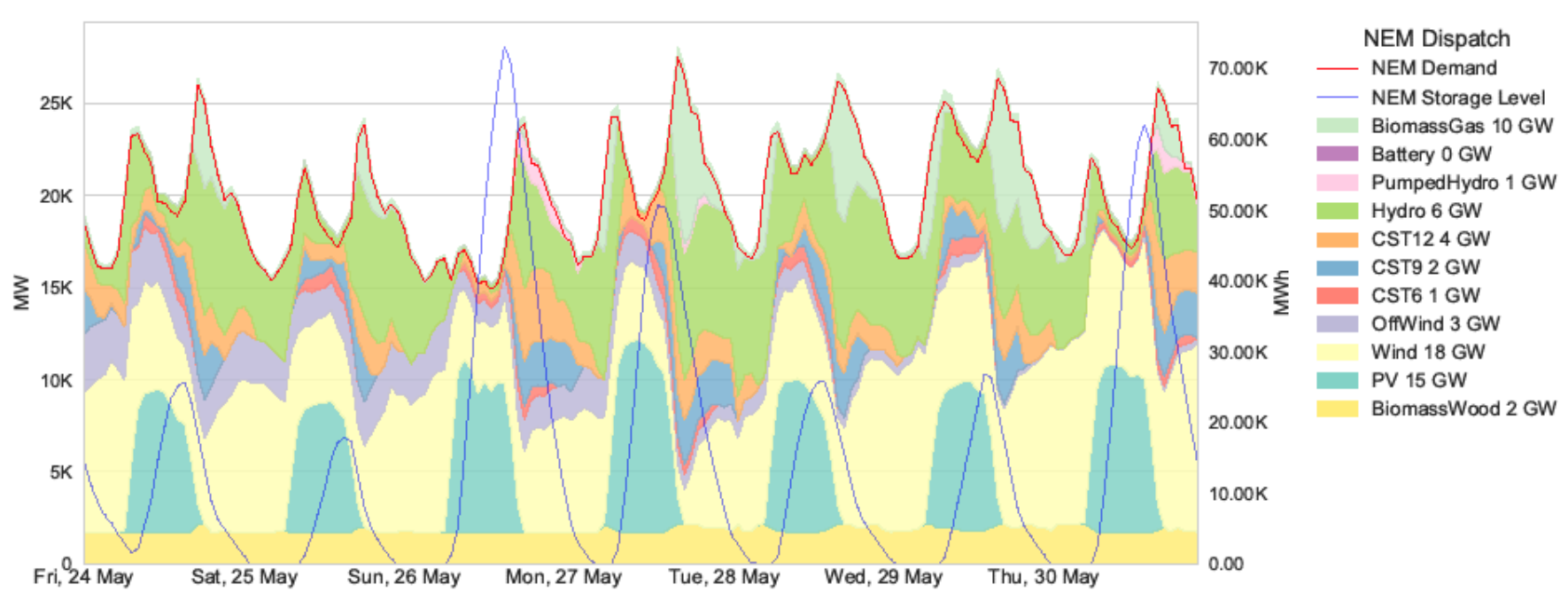

Figure 8: Winter dispatch chart in low demand scenario

\section{Conclusion}

The recent ratification of the Paris Climate Change Agreement has significant implications for Australia given its emissions intensive economy. Given the juxtaposition of an emissions intensive electricity sector with abundant renewable energy resources, it is likely that this sector will need to decarbonize for Australia to meet medium- and long-term emissions reduction targets. To address a gap in studies of 100 per cent renewable electricity systems, this paper explored the impact of CST with different sizing of thermal storage. This paper explored the potential role of CST in a 100 per cent renewable NEM system under different scenarios of CST configuration and subjected the results to sensitivity analysis.

A genetic algorithm (GA) was chosen as the optimization algorithm to seek the least cost combination of renewable generation technologies, transmission interconnectors and storage capacity in the NEM system. The main finding is that the scenario where all three CST configurations (six, nine, and twelve hours of thermal storage) can be deployed achieves a lower system cost than scenarios where the size of thermal storage coupled with CST is limited to one option. This result was robust to an increase in the real discount rate from $5 \%$ to $10 \%$ p.a.

The results also showed that there seemed to be a limited role for utility scale battery storage in the NEM when many CST configurations are available to be deployed. However, the sensitivity analysis showed that if the capital cost for CST is much higher than assumed in the main scenarios, then increased deployment of battery storage was economic. It is also possible that given the hourly temporal resolution of the modelling in this paper, battery storage could be undervalued compared to a finer temporal resolution model, since batteries could provide frequency control ancillary services and faster ramping in shorter time scales.

The sensitivity analysis also showed that the scenario results are sensitive to assumptions of renewable resource availability. Similar to previous studies, this paper found that meeting demand during winter evenings is the most challenging time period for a 100 per cent 
renewable NEM power system. This finding underscores the importance of sufficient capacity of non-intermittent renewable generation to be available for dispatch during winter evenings. It also suggests that more flexible demand may have a role to limit the amount of additional capacity required. This in an important avenue for future research.

\section{References}

[1] A. Denis, P. Graham, S. Hatfield-Dodds, F. Jotzo, Introduction, in: W. Sue, S. Ferraro, N. Kautto, A. Skarbek, J. Thwaites (Eds.), Pathways to Deep Decarbonisation 2050 How Aust. Can Prosper a Low Carbon World, ClimateWorks Australia, Melbourne, 2014: pp. 5-21.

[2] Department of Industry Innovation and Science, Australian Energy Update, Canberra, 2016.

[3] Geoscience Australia and ABARE, Australian Energy Resource Assessment, Canberra, 2010. http://www.ga.gov.au/corporate_data/70142/70142_complete.pdf.

[4] M.Z. Jacobson, M.A. Delucchi, Providing all global energy with wind, water, and solar power, Part I: Technologies, energy resources, quantities and areas of infrastructure, and materials, Energy Policy. 39 (2011) 1154-1169. doi:10.1016/j.enpol.2010.11.040.

[5] T.H.Y. Føyn, K. Karlsson, O. Balyk, P.E. Grohnheit, A global renewable energy system: A modelling exercise in ETSAP/TIAM, Appl. Energy. 88 (2011) 526-534. doi:10.1016/j.apenergy.2010.05.003.

[6] M.A. Delucchi, M.Z. Jacobson, Providing all global energy with wind, water, and solar power, Part II: Reliability, system and transmission costs, and policies, Energy Policy. 39 (2011) 1170-1190. doi:10.1016/j.enpol.2010.11.045.

[7] WWF, The Energy Report: 100\% Renewable Energy by 2050, Switzerland, 2011.

[8] M.Z. Jacobson, M.A. Delucchi, A path to sustainable energy by 2030, Sci Am. 301 (2009) 58-65. http://www.ncbi.nlm.nih.gov/pubmed/19873905.

[9] V. Fthenakis, J.E. Mason, K. Zweibel, The technical, geographical, and economic feasibility for solar energy to supply the energy needs of the US, Energy Policy. 37 (2009) 387-399. doi:10.1016/j.enpol.2008.08.011.

[10] B.A. Frew, S. Becker, M.J. Dvorak, G.B. Andresen, M.Z. Jacobson, Flexibility mechanisms and pathways to a highly renewable US electricity future, Energy. 101 (2016) 65-78. doi:10.1016/j.energy.2016.01.079.

[11] CAT, Zero Carbon Britain 2030: A New Energy Strategy, Powys, 2010.

[12] B. Sorensen, A renewable energy and hydrogen scenario for northern Europe, Int. J. Energy Res. 32 (2008) 471-500. doi:Doi 10.1002/Er.1376. 
[13] EREC, Re-thinking 2050: a 100\% renewable energy vision for the European Union, 2010.

[14] PWC, 100\% renewable electricity: a roadmap to 2050 for Europe and North Africa, 2010.

[15] W. Liu, H. Lund, B. V Mathiesen, X.L. Zhang, Potential of renewable energy systems in China, Appl. Energy. 88 (2011) 518-525. doi:DOI 10.1016/j.apenergy.2010.07.014.

[16] H. Lund, B. V Mathiesen, Energy system analysis of $100 \%$ renewable energy systemsThe case of Denmark in years 2030 and 2050, Energy. 34 (2009) 524-531. doi:10.1016/j.energy.2008.04.003.

[17] SRU, Pathways Towards a 100\% Renewable Electricity System: Technical Report, 2011.

[18] D. Connolly, H. Lund, B. V Mathiesen, M. Leahy, The first step towards a $100 \%$ renewable energy-system for Ireland, Appl. Energy. 88 (2011) 502-507. doi:10.1016/j.apenergy.2010.03.006.

[19] M. Esteban, Q. Zhang, A. Utama, Estimation of the energy storage requirement of a future 100\% renewable energy system in Japan, Energy Policy. 47 (2012) 22-31. doi:10.1016/j.enpol.2012.03.078.

[20] I.G. Mason, S.C. Page, A.G. Williamson, A 100\% renewable electricity generation system for New Zealand utilising hydro, wind, geothermal and biomass resources, Energy Policy. 38 (2010) 3973-3984. doi:10.1016/j.enpol.2010.03.022.

[21] G. Krajačić, N. Duić, M. da G. Carvalho, How to achieve a 100\% RES electricity supply for Portugal?, Appl. Energy. 88 (2011) 508-517.

[22] M. Wright, P. Hearps, Zero carbon Australia stationary energy plan, Melbourne, 2010.

[23] Australian Energy Market Operator (AEMO), 100 Per Cent Renewables Study Modelling Outcomes, Melbourne, 2013.

[24] B. Elliston, M. Diesendorf, I. MacGill, Simulations of scenarios with $100 \%$ renewable electricity in the Australian National Electricity Market, Energy Policy. 45 (2012) 606613. doi:http://dx.doi.org/10.1016/j.enpol.2012.03.011.

[25] B. Elliston, I. MacGill, M. Diesendorf, Comparing least cost scenarios for $100 \%$ renewable electricity with low emission fossil fuel scenarios in the Australian National Electricity Market, Renew. Energy. 66 (2014) 196-204. doi:10.1016/j.renene.2013.12.010.

[26] B. Elliston, I. MacGill, M. Diesendorf, Least cost 100\% renewable electricity scenarios in the Australian National Electricity Market, Energy Policy. 59 (2013) 270-282. doi:http://dx.doi.org/10.1016/j.enpol.2013.03.038. 
[27] R. Huva, R. Dargaville, S. Caine, Prototype large-scale renewable energy system optimisation for Victoria, Australia, Energy. 41 (2012) 326-334.

doi:http://dx.doi.org/10.1016/j.energy.2012.03.009.

[28] B. Elliston, J. Riesz, I. MacGill, What cost for more renewables? The incremental cost of renewable generation - An Australian National Electricity Market case study, Renew. Energy. 95 (2016) 127-139. doi:10.1016/j.renene.2016.03.080.

[29] J. Riesz, J. Gilmore, I. Macgill, Assessing the viability of Energy-Only Markets with 100\% Renewables : An Australian National Electricity Market Case Study, Econ. Energy Environ. Policy. 5 (2016) 105-130.

[30] R. Welters, L. Reedman, W. Mitchell, Job impacts of a decarbonised Australian economy, in: Proceedings of the 13th Path to Full Employment and 18th National Unemployment Conference, Newcastle, QLD, Australia, 2011: pp. 234-251.

[31] C. Budischak, D. Sewell, H. Thomson, L. Mach, D.E. Veron, W. Kempton, Costminimized combinations of wind power, solar power and electrochemical storage, powering the grid up to $99.9 \%$ of the time, J. Power Sources. 225 (2013) 60-74.

[32] Bureau of Resources and Energy Economics, Australian Energy Technology Assessment, 2012.

[33] Australian Energy Market Operator (AEMO), Demand Trace Development for the 2015 National Transmission Network Development, (2015) 1-12. http://www.aemo.com.au/Electricity/Planning/Related-Information/PlanningAssumptions.

[34] CO2CRC, Australian power generation technology report, Melbourne, 2015.

[35] Australian Energy Market Operator (AEMO), 100 percent renewable study - modelling assumptions and input, 2012.

[36] Australian Energy Market Operator (AEMO), Generation Information, 2016.

[37] T.S. Brinsmead, P. Graham, J. Hayward, E. Ratnam, L. Reedman, Future energy storage trends: An assessment of the economic viability, potential uptake and impacts of electrical energy storage on the NEM 2015-2035, Australia, 2015.

[38] M.A. Meybodi, A.C. Beath, Impact of cost uncertainties and solar data variations on the economics of central receiver solar power plants: An Australian case study, Renew. Energy. 93 (2016) 510-524. doi:10.1016/j.renene.2016.03.016.

[39] Australian Energy Market Operator (AEMO), Generation Expansion Plan, 2014.

[40] K. Schaber, F. Steinke, T. Hamacher, Transmission grid extensions for the integration of variable renewable energies in Europe: Who benefits where?, Energy Policy. 43 (2012) 123-135. doi:10.1016/j.enpol.2011.12.040. 
[41] S. Dunstall, T. ElGindy, N. Jafari, M. Ayre, A.T. Ernst, P. Graham, L. Reedman, M. Savelsbergh, S. Woodman, Accounting for renewable energy supply intermittency in energy systems modelling, 20th Int. Congr. Model. Simul. (2013) 1509-1515.

[42] Australian Energy Market Operator (AEMO), Capacity expansion modelling, 2014.

[43] M.Z. Jacobson, R.W. Howarth, M.A. Delucchi, S.R. Scobie, J.M. Barth, M.J. Dvorak, M. Klevze, H. Katkhuda, B. Miranda, N.A. Chowdhury, Response to comment on paper examining the feasibility of changing New York state's energy infrastructure to one derived from wind, water, and sunlight, Energy Policy. 62 (2013) 1212-1215. doi:10.1016/j.enpol.2013.07.105. 